\title{
Numerical Investigation of Natural Convection Heat Transfer in Porous Medium Saturated With Carbon Dioxide in Supercritical State
}

\author{
Dr. Amir S. Dawood, Younis M. Najim, Mohanad K. Radhi \\ Department of Mechanical Engineering- Mosul University
}

\begin{abstract}
Natural convection in a porous medium saturated with supercritical carbon dioxide $\left(\mathrm{CO}_{2}\right)$ which is bounded by square cavity is studied numerically by solving the governing Darcy equation using finite-differences method. The side walls of cavity were assumed to be isotherm with fixed temperature difference of $0.0152 \mathrm{~K}$, while the upper and lower sides are assumed to be thermally insulated, the aspect ratio is chosen to be one, with cavity height of $0.01 \mathrm{~m}$, the Darcy number adopted is $10^{-5}$, usually these values lead to very small modified Rayleigh number. Despite all of this, the state of supercritical takes the fluid $\left(\mathbf{C O}_{2}\right)$ to a huge changes in its properties $\left(C_{p}, \rho, \mu, \beta\right)$ which allow to transfer a relatively large amount of heat between the hot and cold sides of the cavity with a very small temperature difference with maximum Nusselt number over 13 . The results of this study show clearly these concepts. The state of carbon dioxide in supercritical region is specified by reduced pressure $P_{r e}=P / P_{c}$ and reduced temperature $T_{r e}=T_{a} / T_{c}$, the reduced temperature and pressure have been varied as $T_{r e}: 1.002-1.072, P_{r e}: 1.1-2.0$.
\end{abstract}

Keyword: Natural convection, porous media, supercritical carbon dioxide,
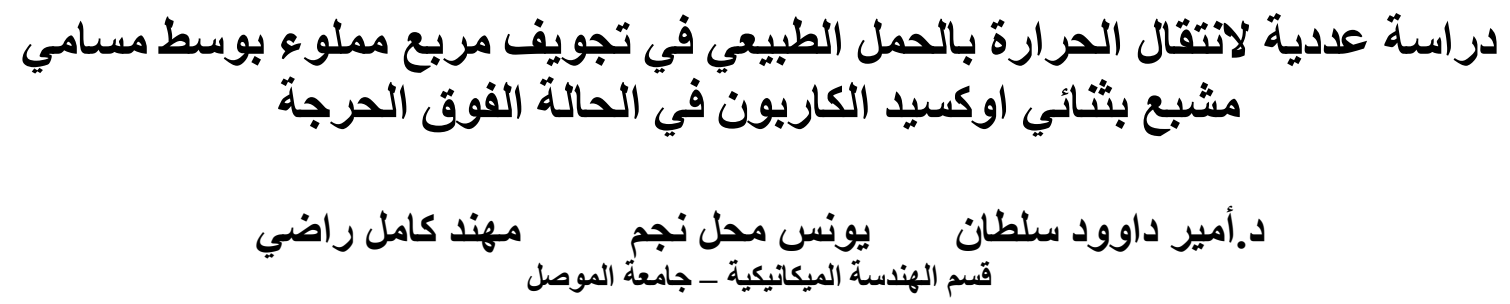

\section{الخلاصة}

تناولت هذه الدراسة التحليل العددي بطريقة الفروق المحددة لانتقال الحرارة بالحمل الطبيعي داخل تجويف

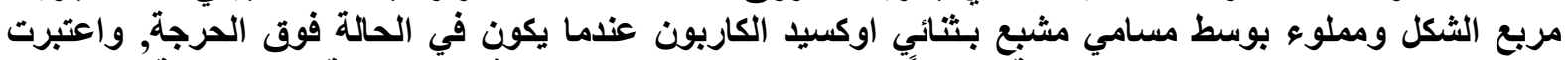

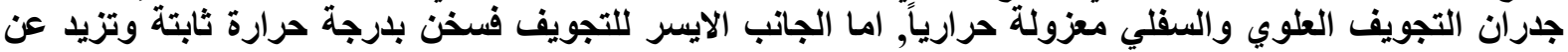

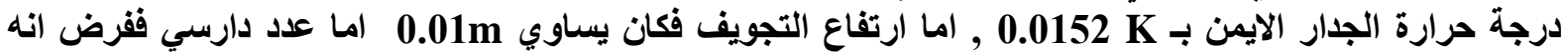

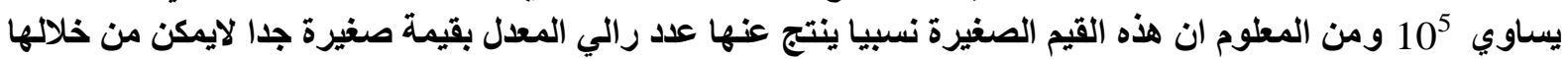

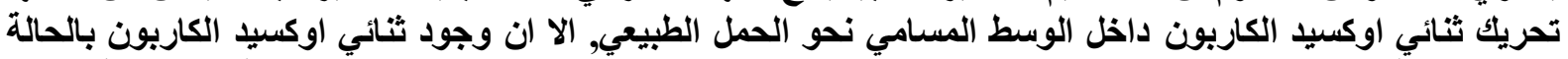

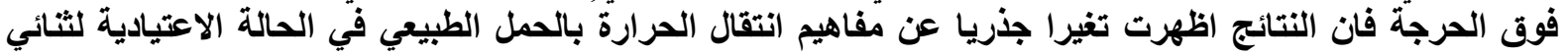

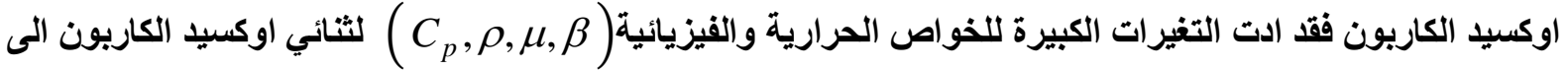

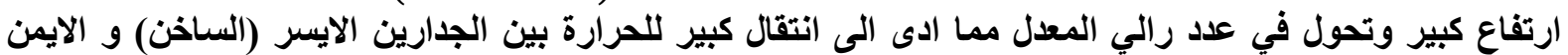

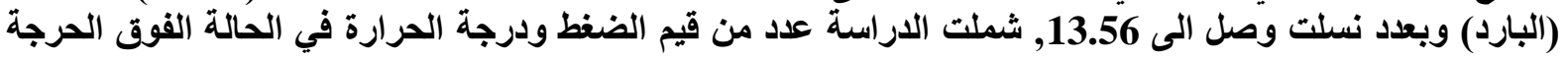

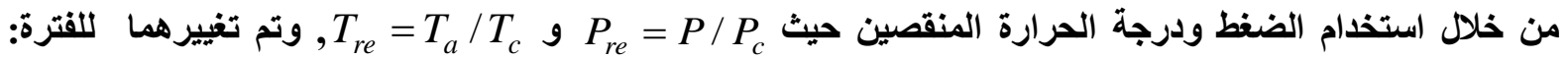
$T_{r e}: 1.002-1.072, P_{r e}: 1.1-2.0$ 


\begin{tabular}{|c|c|c|c|}
\hline \multicolumn{2}{|c|}{ Nomenclature } & \multicolumn{2}{|r|}{ Greek Symbols } \\
\hline A, a & Parameters in Eq. (13) & $\alpha$ & Thermal diffusivity, $\left[\mathrm{m}^{2} / \mathrm{s}\right]$ \\
\hline $\mathrm{AR}$ & cavity aspect ratio $=\mathrm{L} / \mathrm{H},[-]$ & $\beta$ & $\begin{array}{l}\text { Coefficient of thermal expansion, [ } \\
1 / \mathrm{K}]\end{array}$ \\
\hline $\mathrm{B}, \mathrm{b}$ & Parameters in Eq. (14) & $v$ & kinematic viscosity $\left[\mathrm{m}^{2} / \mathrm{s}\right]$ \\
\hline $\mathrm{Cp}$ & specific heat at constant pressure $[\mathrm{kJ} / \mathrm{kg} \mathrm{K}]$ & $\theta$ & dimensionless temperature[-] \\
\hline $\mathrm{G}$ & Gravitational acceleration $\left[\mathrm{m} / \mathrm{s}^{2}\right]$ & $\Psi$ & dimensionless stream function[-] \\
\hline $\mathrm{Da}$ & Darcy number & $\psi$ & dimensional stream function $\left(\mathrm{m}^{2} / \mathrm{s}\right)$ \\
\hline $\mathrm{L}$ & Cavity height $[\mathrm{m}]$ & $\omega$ & dimensional vorticity (1/s) \\
\hline $\mathrm{k}$ & Thermal conductivity $[\mathrm{W} / \mathrm{m} \cdot \mathrm{K}]$ & $\rho$ & density $\left(\mathrm{kg} / \mathrm{m}^{3}\right)$ \\
\hline $\mathrm{Nu}$ & Mean Nusselt number & $\mu$ & dynamic viscosity $\left[\mathrm{N} \mathrm{s} / \mathrm{m}^{2}\right]$ \\
\hline $\mathrm{P}$ & Pressure $[\mathrm{Pa}]$ & $\Delta T$ & Temperature difference, $[\mathrm{K}]$ \\
\hline Pre & Reduced pressure [-] & \multirow{2}{*}{\multicolumn{2}{|c|}{ Subscript }} \\
\hline $\mathrm{R}$ & Universal Gas constant, $[\mathrm{J} / \mathrm{mol} \cdot \mathrm{K}]$. & & \\
\hline $\mathrm{Ra}_{\mathrm{m}}$ & Modified Rayleigh number. & $c$ & Critical condition \\
\hline $\mathrm{RC}$ & Relation coefficient [-] & $a$ & Fluid \\
\hline $\mathrm{Rg}$ & Multiple regression. & re & Reduced \\
\hline$T$ & Dimensional temperature $[\mathrm{K}]$. & & \\
\hline Tre & Reduced temperature [-] & & \\
\hline $\mathrm{u}, \mathrm{v}$ & $\begin{array}{l}\text { Dimensional } \mathrm{x} \text { and } \mathrm{v} \text { components of } \\
\text { velocity }[\mathrm{m} / \mathrm{s}]\end{array}$ & & \\
\hline $\mathrm{U}, \mathrm{V}$ & $\begin{array}{l}\text { Dimensionless } \mathrm{x} \text { and } \mathrm{v} \text { components of } \\
\text { velocity[-] }\end{array}$ & & \\
\hline $\mathrm{H}$ & Cavity width $[\mathrm{m}]$ & & \\
\hline $\mathrm{x}, \mathrm{y}$ & dimensionless coordinates. & & \\
\hline $\mathrm{Y}, \mathrm{X}$ & Non-dimensional Cartesian coordinates. & & \\
\hline $\mathrm{Z}$ & Compressibility factor. & & \\
\hline
\end{tabular}

\section{Introduction:}

Supercritical carbon dioxide refers to carbon dioxide that is in a fluid state while also being at or above both its critical temperature and pressure, yielding rather uncommon properties. Carbon dioxide usually behaves as a gas in air at standard conditions for temperature and pressure (STP) or as a solid called dry ice when frozen. If the temperature and pressure are both increased from STP to be at or above the critical point for carbon dioxide, it can adopt properties midway between a gas and a liquid. More specifically, it behaves as a supercritical fluid above its critical temperature $\left(30.978{ }^{\circ} \mathrm{C}\right)$ and critical pressure (73.773 bar), expanding to fill its container like a gas but with a density like that of a liquid. Supercritical CO2 is becoming an important commercial and industrial solvent due to its role in chemical extraction in addition to its low toxicity and environmental impact. The relatively low temperature of the process and the stability of $\mathrm{CO} 2$ also allow most compounds to be extracted with little damage or denaturing. Supercritical carbon dioxide is seen as a promising green solvent because it is non-toxic, and a byproduct of other industrial processes. Furthermore, separation of the reaction components from the starting material is much simpler than with traditional organic solvents. $[3,4,5]$

This paper present a study of natural convection on porous media saturated with carbon dioxide where its temperature and pressure above the critical point $\left(30.978{ }^{\circ} \mathrm{C}, 73.773 \mathrm{bar}\right)$. Convection heat transfer of fluids at supercritical pressures has many special features due to the sharp variations of the thermophysical properties, In recent years, the interest in heat transfer of fluids at supercritical pressures for different geometry configuration has been 
increasing $[5,6,7]$, driven by the need to develop the nuclear reactors using the supercritical $\mathrm{CO} 2$ indirect cycle, compact gas coolers and internal heat exchangers for the high-pressure $\mathrm{CO} 2$ trans-critical compression cycle in air conditioners and heat pumps, [8]. Most previous papers studied the average heat transfer performance in mini/micro tubes. However, the average heat transfer performance in the square cavity is very important to understand the heat transfer mechanism.

Considerable interest in heat transfer to fluids at pressures above the thermodynamic critical value was stimulated during the 1950s and 1960s by the introduction of fossil-fuelled power plant water steam generators operating at supercritical pressure. A comprehensive review of such studies was reported by Jackson and Hall [1], the natural convection from a heated, vertical flat plate into a supercritical fluid has been investigated by Rolando A.[4], an Experimental and numerical study of convection heat transfer of $\mathrm{CO} 2$ at supercritical pressures in vertical porous tubes is studied by Pei-Xue Jiang et al. [9] and S. He et al. [8], proposed computational simulations are reported of experiments on convective heat transfer to carbon dioxide at a pressure of 75.8 bar, which is just above the thermodynamic critical value of 73.8 bar. These have been carried out using a variable property, elliptic computational formulation incorporating low Reynolds number turbulence models. Also, heat transfer from supercritical carbon dioxide flowing in horizontal mini/micro circular tubes cooled at a constant temperature. Six stainless steel circular tubes having inside-diameters of $0.50 \mathrm{~mm}, 0.70 \mathrm{~mm}, 1.10 \mathrm{~mm}, 1.40 \mathrm{~mm}, 1.55 \mathrm{~mm}$, and $2.16 \mathrm{~mm}$, has been investigated experimentally by S. M. Liao et al.[12].

\section{Mathematical formulation and description of the problem}

The schematic configuration of the considered twodimensional square cavity filled with porous media saturated with carbon dioxide in supercritical state, coordinates and boundary conditions are shown in Fig.(1). The height of the cavity (L) is selected to be $0.01 \mathrm{~m}$, and for aspect ratio of 1.0. the upper and lower walls of the cavity are assumed to be thermally insulated, the cavity heated from left side and cooled from right side with a fixed temperature difference of $0.0152 \mathrm{~K}$ between the hot and cold sides.

The value of Darcy number is also considered to be constant at $10^{-5}$ therefore the value of term $\triangle T L^{3} \mathrm{Da}$ is $1.52 \times 10^{-13}$ and this value is very small in the traditional

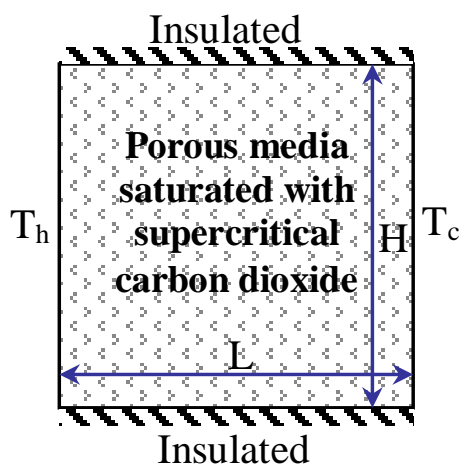

Fig. (1) Schematic diagram of the problem. natural convection calculation for cavity geometry filled with porous media. The system was considered to be two-dimensional, steady-state and the density variations with temperature are negligible excepting the buoyancy terms. The fluid is assumed to be in thermal equilibrium with the porous matrix, also the inertia terms and viscous dissipations are neglected, and therefore the Boussinesq approximation and Darcy's law are assumed to be valid. However, the governing equations can be written as, $[2,3]$ :

$$
\begin{aligned}
& \frac{\partial u}{\partial x}+\frac{\partial v}{\partial y}=0 \\
& \frac{\partial u}{\partial y}-\frac{\partial v}{\partial x}=-\frac{g K \beta}{v} \frac{\partial T}{\partial y} \\
& u \frac{\partial T}{\partial x}+v \frac{\partial T}{\partial y}=\alpha\left(\frac{\partial^{2} T}{\partial x^{2}}+\frac{\partial^{2} T}{\partial y^{2}}\right)
\end{aligned}
$$


A further simplification of Equations (1) - (3) is afforded by the introduction of the non-dimensional stream function $\psi$ along with the usual variables defined as follows:

$$
\begin{aligned}
& \frac{\partial^{2} \widehat{\psi}}{\partial X \partial Y}+\frac{\partial^{2} \widehat{\psi}}{\partial Y \partial X}=0 \\
& \frac{\partial^{2} \widehat{\psi}}{\partial X^{2}}+\frac{\partial^{2} \widehat{\psi}}{\partial Y^{2}}=-R a_{m} \frac{\partial \theta}{\partial X} \\
& \frac{\partial \widehat{\psi}}{\partial Y} \cdot \frac{\partial \theta}{\partial X}-\frac{\partial \widehat{\psi}}{\partial X} \cdot \frac{\partial \theta}{\partial Y}=\left(\frac{\partial^{2} \theta}{\partial X^{2}}+\frac{\partial^{2} \theta}{\partial Y^{2}}\right)
\end{aligned}
$$

The non-dimensional continuity, momentum and energy equation are expressed respectively as the following:

$$
\begin{aligned}
& X=\frac{x}{L}, \quad Y=\frac{y}{L}, A R=\frac{W}{L} \\
& \theta=\frac{T-T_{c}}{T_{h}-T_{c}} \\
& u=\frac{L}{\alpha} * \frac{\partial \hat{\psi}}{\partial Y}, v=-\frac{L}{\alpha} * \frac{\partial \hat{\psi}}{\partial X}
\end{aligned}
$$

at $: Y=0,0 \leq X \leq A R \Rightarrow \frac{\partial \theta}{\partial X}=0, \widehat{\psi}=V=0$

at: $Y=1,0 \leq X \leq A R \Rightarrow \frac{\partial \theta}{\partial X}=0, \widehat{\psi}=V=0$

at $: X=0,0 \leq Y \leq 1 \Rightarrow \theta=1, \widehat{\psi}=U=0$

at : $X=A R, 0 \leq Y \leq 1 \Rightarrow \theta=0, \widehat{\psi}=U=0$

An expression for the Nusselt number is easily found:-

$$
N u=-\left.\frac{1}{A R} \int_{0}^{A R} \frac{\partial \theta}{\partial X}\right|_{X=0} d y
$$

\section{Solution procedure and numerical test:}

\section{a. Calculation of thermo physical properties of $\mathrm{CO}_{2}$ :}

The thermo physical properties of carbon dioxide $\mathrm{CO}_{2}$ in supercritical state is estimated using Engineering Equation Solver (EES) employing the property function and parametric table, any state in supercritical region is specified by temperature and pressure $\left(T_{a}, P\right)$, in parametric table, for each value of $P_{r e}$, there are 1000 value of $T_{r e}$ start from 1.002 to 1.072 (with a step of $7 \times 10^{-5}$ ) then the $\left(T_{a}, P\right)$ are calculated as $T_{a}=T_{r e} T_{c}, P=P_{r e} P_{c}$ then the EES property function is used to find the thermo physical properties, One of the most important characteristics of supercritical fluids near their critical points is that their physical properties exhibit extremely rapid variations with a change in temperature, especially near the pseudo critical point (the temperature at which the specific heat reaches a peak for a given pressure, see fig. (2). 

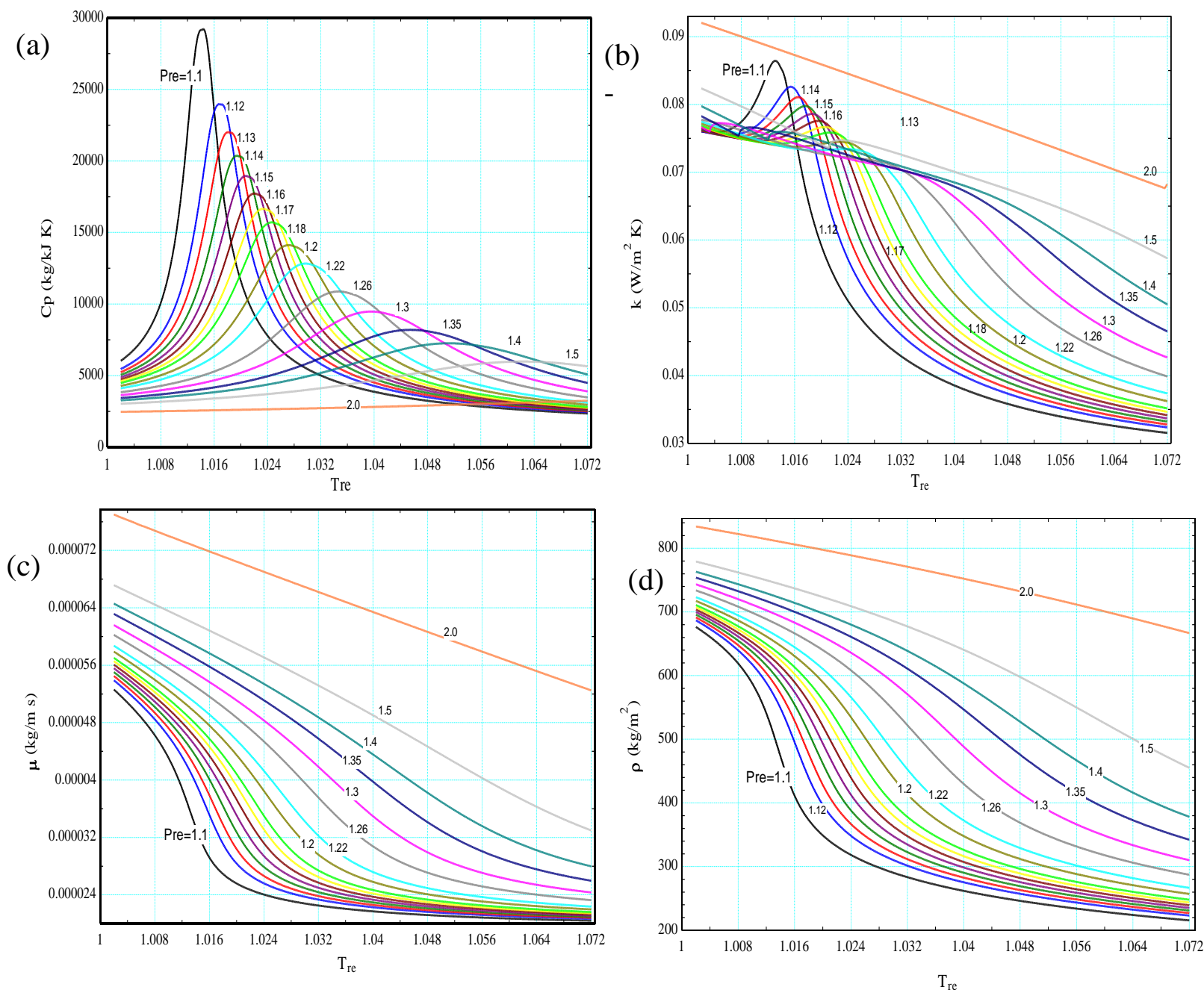

$\mathrm{T}_{\mathrm{re}}$

(e)-

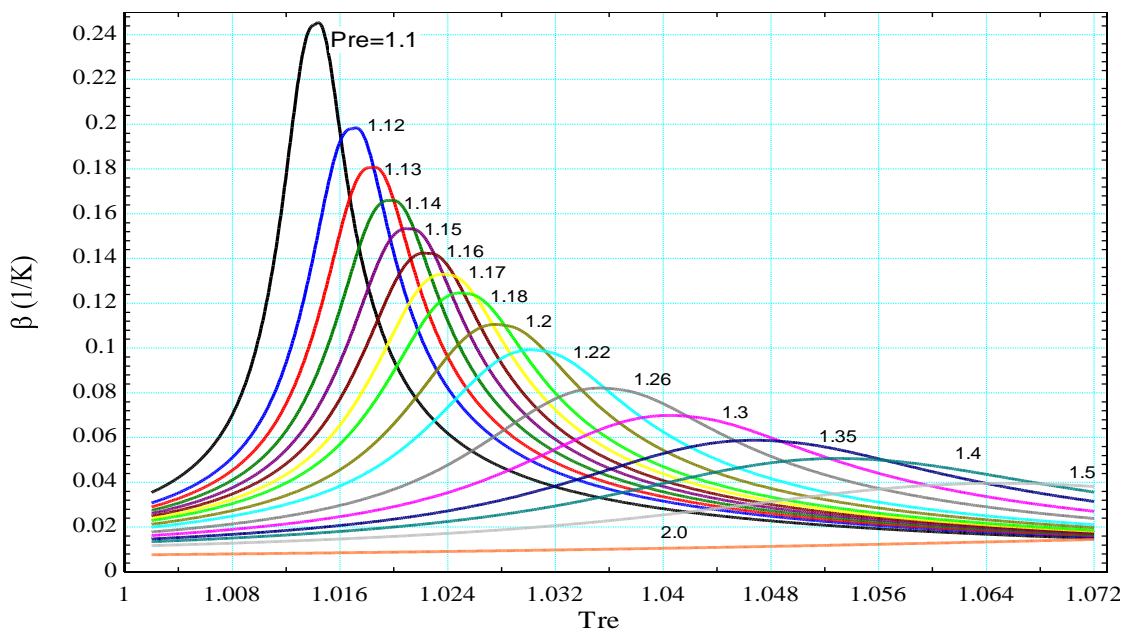

Fig. (2) Thermo physical properties of carbon dioxide $\left(\mathrm{CO}_{2}\right)$ where:
a- Heat capacity at constant pressure $\mathrm{C}_{\mathrm{p}}$ in $\mathrm{kJ} / \mathrm{kg} \mathrm{K}$.
b- Thermal conductivity $\mathrm{k}$ in $\mathrm{W} / \mathrm{m}^{2} \mathrm{~K}$.
c- Viscosity in $\mathrm{kg} / \mathrm{m} \mathrm{s}$.
d- Density in $\mathrm{kg} / \mathrm{m}^{3}$.
e- Thermal expansion coefficient $\beta$ in $1 / \mathrm{K}$. 


\section{b. Calculation of thermal expansion coefficient of $\mathrm{CO}_{2}$ :}

The general form for equation of state has been presented by Schmidt and Wenzel [8], their equation is suitable at high pressures and temperatures such as in the case of supercritical fluids processes, under the van der Waals equation of state assumption, the equation of compressibility factor is, [ ]:

$$
Z^{3}-(B+1) Z^{2}+A Z-A B=0
$$

Where:

$$
\begin{aligned}
& Z=\frac{P V^{\prime}}{R T_{a}} \\
& A=\frac{a P}{\left(R T_{a}\right)^{2}}, a=\frac{27}{64} \frac{\left(R T_{c}\right)^{2}}{P_{c}} \\
& B=\frac{b P}{R T_{a}}, b=\frac{1}{8} \frac{R T_{c}}{P_{c}}
\end{aligned}
$$

The expansion for $\beta$ as a function of compressibility factor, pressure, and temperature is:

$\beta=\frac{1}{T_{a}}\left[1-\left(\frac{Z^{2} B-2 Z A+3 A B}{3 Z^{3}-2 Z^{2}(B+1)+Z A}\right)\right]$

The calculation of $\beta$ involves two steps:

1- Find the parameters $A$ and $B$ then the compressibility factor $(Z)$ is determined by finding the appropriate root of Eq. (11).

2- Calculate the thermal expansion $\beta$ by Substituting Z, A, B and T in the Eq. (15). The temperature $\mathrm{T}$ represent the fluid temperature and $T_{a}=T_{r e} T_{c}$.

\section{c. Numerical solution of governing equations:}

After calculation of modified Rayleigh number, the finite difference method was employed to solve the non-dimensional governing equations, second order finite differences approximation were used to obtain the numerical form of the partial derivatives in governing equations, the central difference approximation is used for the interior nodes, while the forward and backward differences approximation are used for the boundary nodes. After arranging the governing equations, a computer code written in FORTRAN language was prepared specially for solving this problem, the (over and under relaxation) technique was employed to hasten the speed of convergence, the criterion of convergence was assumed to satisfy the following condition:

$$
\sum_{i=1}^{I X-1} \sum_{j=1}^{J Y-1} \frac{\left|\theta_{(i, j)}^{n+1}-\theta_{(i, j)}^{n}\right|}{\theta_{(i, j)}^{n+1}} \leq 10^{-5}
$$

Many grid sizes were tested to satisfy minimum error between the lower and upper Nusselt numbers, the best grid size was found to be $(120 \times 120)$. 


\section{Results and discussion:}

In this part of the paper, the results of heat transfer by natural convection in porous cavity filled with carbon dioxide near the supercritical condition were presented and discussed. Fluid properties represented by specific heat, thermal conductivity, viscosity, density, and thermal expansion coefficient were calculated in the vicinity of supercritical conditions were the reduced pressure and reduced temperature approach the unity. The calculations were performed so that the turbulence conditions wouldn't be reached by keeping Reynolds number based on cavity width under turbulence limit ( i.e. $\operatorname{Re}<10^{5}$ ). The main parameter under which the runs were executed are the reduced pressure $\left(P_{r e}\right)$ and the reduced temperature $\left(T_{r e}\right)$, the output results of each run were: average Nusselt number, modified Rayleigh number, streamlines contour and isotherms over the cavity. The reduced pressure was ranged from 1.1 to 2.0 and for each value of $P_{r e}$ there is 36 value of reduced temperature ranging from 1.002 to 1.072 .

The results show an important point that is the ability of supercritical carbon dioxide to transfer large amount of heat with respect to carbon dioxide in normal state, where the same condition of temperature difference, Darcy number and cavity dimensions have been tested in each state. In the normal state the maximum value of Ram obtained is $2.673 \times 10^{-4}$ where no convection flow has been induced, while the supercritical test show that the maximum Ram is 835.64 in which the natural convection is dominant with Nusselt number of 13.56 this value refers to good exchange of heat in natural convection mode.

Fig.(3) exhibits the effect of reduced temperature on Nusselt number and modified Rayleigh number under different values of the reduced pressure. Fig.(3-a) demonstrates the behavior of average Nusselt number near and above the critical condition of $\mathrm{CO} 2$, the numeric data of that figure was represented in Table (1). It is seen that there was a peak of Nusselt number for each pressure near the corresponding pseudo-critical temperature (the temperature at which the specific heat reaches the maximum value under constant pressure), that behavior is attributed to the sharp increase of thermo physical properties at such point. Beyond the pseudo-critical temperature, Nusselt number decreases until reaching constant value not affected by the reduced temperature propagation, also it is noticed that maximum Nusselt number decreases with the reduced pressure increase, that returns to the decaying of thermophysical properties due to pressure increase over the critical value.

Fig . (3-b) and (3-c) show the behavior of modified Rayleigh number under the supercritical and atmospheric conditions respectively. By compression of both preceding figures, it would be concluded that buoyancy force is enhanced clearly in case of supercritical state. 

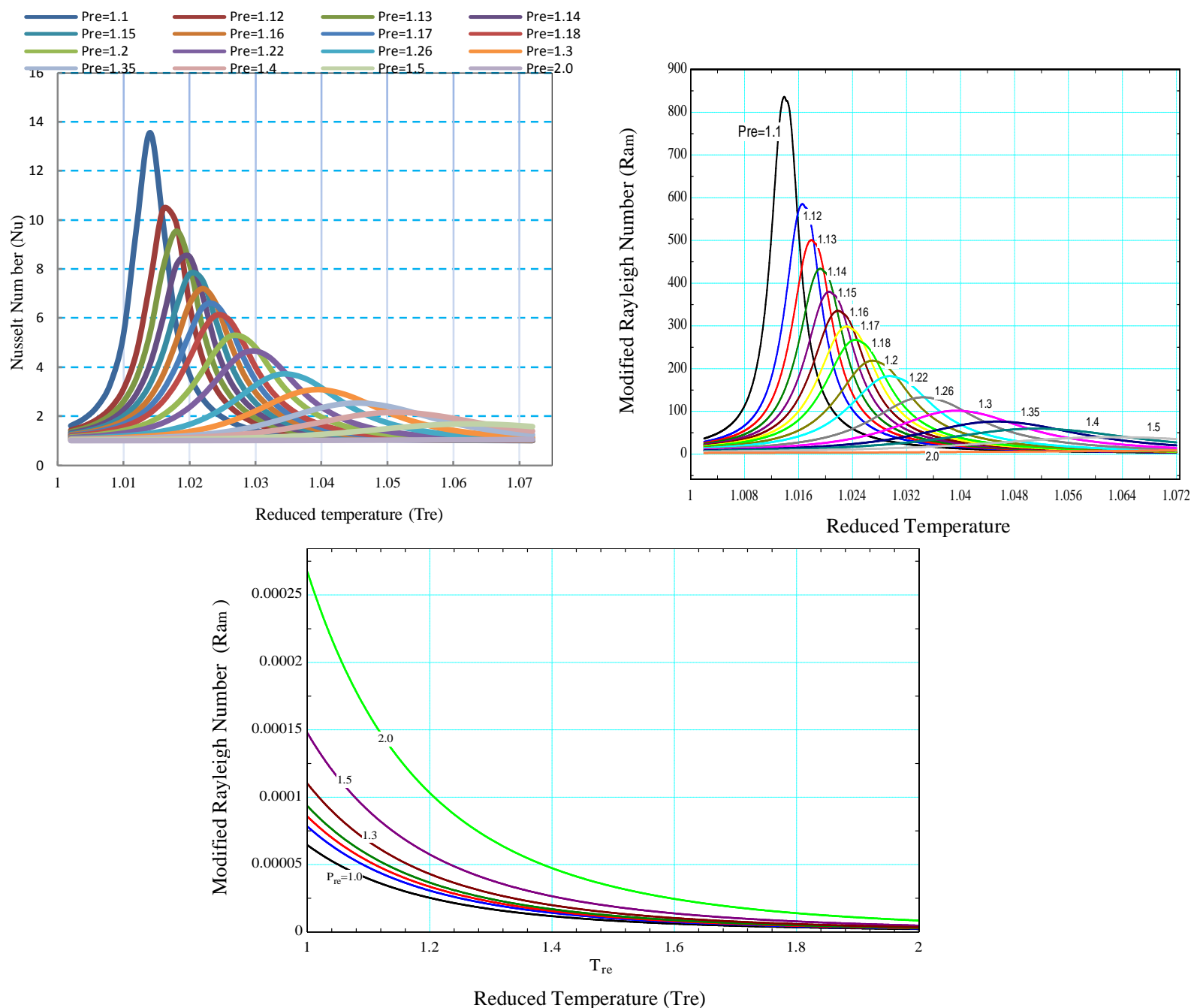

Fig.(3) :

a- Variation of Nusselt number with reduced temperature and pressure.

b- Variation of modified Rayleigh number with $T_{r e}$ and $P_{r e}$ in supercritical state.

c- Variation of modified Rayleigh number with $T_{r e}$ and $P_{r e}$ in normal state.

Fig.(4) and Fig(5) represent the isotherms and streamline contours over the porous cavity at pseudo-critical points. By simple comparison between Fig.(4-a) which is taken as near as possible to the critical point and Fig. (5-h) which is taken as far as possible above the critical point, you can see the differences in temperature gradient and flow intensity for both cases. As shown, it can be noticed that the buoyancy effect is more prominent at the vicinity of the critical point that can be demonstrated by observing the densely accumulated isotherms at the thermal boundary layers (lower left and upper right corners) and by the strength of streams. That leads to an allusion: the closer to critical point the higher in thermal expansion coefficient (the main actuator in bouncy force).

That also implies that bouncy forces are weakened by the reduced pressure increase above the critical point.

Employing the statistical package software named STATISTICA 5.5, to obtain the following correlation:

$$
N u=0.6678+0.05197 R_{m}^{0.8285}+e^{\left(-12.216 \frac{P_{r e}^{-3.1935}}{T_{r e}^{-9.9635}}\right)}
$$

The proportion of variance accounted for $99.747 \%$ and $\mathrm{RC}=0.99873$ 
Table (1). Shows the output results of Nusselt number for corresponding values of reduced pressure and temperature

\begin{tabular}{|c|c|c|c|c|c|c|c|c|c|c|c|c|c|c|c|c|}
\hline$\underset{T_{\mathrm{re}}}{\mathbf{P}_{\mathrm{re}}}$ & 1.10 & 1.12 & 1.13 & 1.14 & 1.15 & 1.16 & 1.17 & 1.18 & 1.20 & 1.22 & 1.26 & 1.30 & 1.35 & 1.40 & 1.50 & 2.00 \\
\hline 1.002 & 1.61 & 1.43 & 1.37 & 1.32 & 1.28 & 1.24 & 1.21 & 1.19 & 1.15 & 1.13 & 1.09 & 1.07 & 1.05 & 1.04 & 1.02 & 1.01 \\
\hline 1.004 & 1.90 & 1.60 & 1.50 & 1.43 & 1.37 & 1.32 & 1.28 & 1.24 & 1.19 & 1.16 & 1.11 & 1.08 & 1.06 & 1.04 & 1.03 & 1.01 \\
\hline 1.006 & 2.39 & 1.87 & 1.71 & 1.59 & 1.50 & 1.42 & 1.37 & 1.32 & 1.24 & 1.19 & 1.13 & 1.09 & 1.07 & 1.05 & 1.03 & 1.01 \\
\hline 1.008 & 3.32 & 2.32 & 2.05 & 1.85 & 1.70 & 1.58 & 1.49 & 1.42 & 1.32 & 1.24 & 1.16 & 1.11 & 1.08 & 1.06 & 1.03 & 1.01 \\
\hline 1.010 & 5.34 & 3.12 & 2.60 & 2.25 & 2.01 & 1.82 & 1.68 & 1.57 & 1.42 & 1.31 & 1.19 & 1.13 & 1.09 & 1.07 & 1.04 & 1.01 \\
\hline 1.012 & 9.76 & 4.64 & 3.59 & 2.93 & 2.50 & 2.19 & 1.96 & 1.79 & 1.56 & 1.41 & 1.24 & 1.16 & 1.10 & 1.08 & 1.04 & 1.01 \\
\hline 1.014 & 13.56 & 7.43 & 5.37 & 4.11 & 3.30 & 2.77 & 2.39 & 2.12 & 1.76 & 1.54 & 1.31 & 1.19 & 1.12 & 1.08 & 1.05 & 1.01 \\
\hline 1.016 & 9.87 & 10.44 & 8.05 & 6.01 & 4.62 & 3.69 & 3.06 & 2.62 & 2.06 & 1.73 & 1.39 & 1.24 & 1.14 & 1.10 & 1.05 & 1.01 \\
\hline 1.018 & 5.65 & 9.85 & 9.54 & 8.15 & 6.43 & 5.05 & 4.06 & 3.36 & 2.48 & 2.00 & 1.51 & 1.30 & 1.17 & 1.11 & 1.06 & 1.01 \\
\hline 1.020 & 3.70 & 6.56 & 8.21 & 8.51 & 7.80 & 6.58 & 5.35 & 4.36 & 3.08 & 2.36 & 1.67 & 1.37 & 1.21 & 1.13 & 1.07 & 1.01 \\
\hline 1.022 & 2.71 & 4.33 & 5.58 & 6.90 & 7.53 & 7.20 & 6.44 & 5.47 & 3.85 & 2.85 & 1.88 & 1.48 & 1.26 & 1.15 & 1.07 & 1.01 \\
\hline 1.024 & 2.15 & 3.13 & 3.88 & 4.85 & 5.89 & 6.59 & 6.53 & 6.11 & 4.68 & 3.45 & 2.15 & 1.61 & 1.31 & 1.18 & 1.08 & 1.01 \\
\hline 1.026 & 1.80 & 2.43 & 2.91 & 3.52 & 4.28 & 5.11 & 5.77 & 5.93 & 5.24 & 4.08 & 2.49 & 1.77 & 1.39 & 1.22 & 1.09 & 1.01 \\
\hline 1.028 & 1.57 & 2.00 & 2.31 & 2.71 & 3.22 & 3.83 & 4.50 & 5.07 & 5.24 & 4.55 & 2.87 & 1.98 & 1.48 & 1.26 & 1.11 & 1.01 \\
\hline 1.030 & 1.42 & 1.71 & 1.93 & 2.20 & 2.55 & 2.97 & 3.47 & 4.01 & 4.81 & 4.65 & 3.26 & 2.21 & 1.59 & 1.32 & 1.12 & 1.01 \\
\hline 1.032 & 1.31 & 1.52 & 1.67 & 1.86 & 2.11 & 2.40 & 2.76 & 3.17 & 4.03 & 4.43 & 3.57 & 2.47 & 1.72 & 1.38 & 1.14 & 1.01 \\
\hline 1.034 & 1.24 & 1.39 & 1.49 & 1.63 & 1.80 & 2.02 & 2.27 & 2.58 & 3.29 & 3.92 & 3.72 & 2.72 & 1.87 & 1.46 & 1.17 & 1.01 \\
\hline 1.036 & 1.18 & 1.29 & 1.37 & 1.47 & 1.59 & 1.75 & 1.94 & 2.16 & 2.71 & 3.32 & 3.67 & 2.93 & 2.04 & 1.55 & 1.19 & 1.02 \\
\hline 1.038 & 1.14 & 1.23 & 1.28 & 1.36 & 1.45 & 1.56 & 1.70 & 1.86 & 2.28 & 2.79 & 3.48 & 3.06 & 2.20 & 1.65 & 1.22 & 1.02 \\
\hline 1.040 & 1.11 & 1.18 & 1.22 & 1.27 & 1.34 & 1.42 & 1.53 & 1.65 & 1.97 & 2.37 & 3.16 & 3.08 & 2.34 & 1.76 & 1.26 & 1.02 \\
\hline 1.042 & 1.09 & 1.14 & 1.17 & 1.21 & 1.26 & 1.32 & 1.40 & 1.49 & 1.74 & 2.05 & 2.79 & 3.00 & 2.46 & 1.87 & 1.30 & 1.02 \\
\hline 1.044 & 1.08 & 1.11 & 1.14 & 1.17 & 1.21 & 1.25 & 1.31 & 1.38 & 1.56 & 1.81 & 2.45 & 2.85 & 2.52 & 1.97 & 1.34 & 1.02 \\
\hline 1.046 & 1.06 & 1.09 & 1.11 & 1.13 & 1.16 & 1.20 & 1.24 & 1.30 & 1.44 & 1.63 & 2.16 & 2.63 & 2.53 & 2.05 & 1.39 & 1.02 \\
\hline 1.048 & 1.05 & 1.08 & 1.09 & 1.11 & 1.13 & 1.16 & 1.19 & 1.23 & 1.34 & 1.49 & 1.92 & 2.40 & 2.49 & 2.12 & 1.44 & 1.02 \\
\hline 1.050 & 1.04 & 1.06 & 1.07 & 1.09 & 1.11 & 1.13 & 1.15 & 1.19 & 1.27 & 1.38 & 1.73 & 2.17 & 2.41 & 2.15 & 1.49 & 1.02 \\
\hline 1.052 & 1.04 & 1.05 & 1.06 & 1.07 & 1.09 & 1.10 & 1.13 & 1.15 & 1.21 & 1.30 & 1.58 & 1.96 & 2.29 & 2.16 & 1.54 & 1.03 \\
\hline 1.054 & 1.03 & 1.04 & 1.05 & 1.06 & 1.07 & 1.09 & 1.10 & 1.12 & 1.17 & 1.24 & 1.46 & 1.79 & 2.14 & 2.13 & 1.59 & 1.03 \\
\hline 1.056 & 1.03 & 1.04 & 1.04 & 1.05 & 1.06 & 1.07 & 1.08 & 1.10 & 1.14 & 1.20 & 1.37 & 1.64 & 1.99 & 2.08 & 1.63 & 1.03 \\
\hline 1.058 & 1.02 & 1.03 & 1.04 & 1.04 & 1.05 & 1.06 & 1.07 & 1.08 & 1.12 & 1.16 & 1.30 & 1.52 & 1.85 & 2.00 & 1.66 & 1.03 \\
\hline 1.060 & 1.02 & 1.03 & 1.03 & 1.04 & 1.04 & 1.05 & 1.06 & 1.07 & 1.10 & 1.13 & 1.24 & 1.42 & 1.72 & 1.92 & 1.68 & 1.04 \\
\hline 1.062 & 1.02 & 1.02 & 1.03 & 1.03 & 1.04 & 1.04 & 1.05 & 1.06 & 1.08 & 1.11 & 1.20 & 1.35 & 1.60 & 1.82 & 1.69 & 1.04 \\
\hline 1.064 & 1.02 & 1.02 & 1.02 & 1.03 & 1.03 & 1.04 & 1.04 & 1.05 & 1.07 & 1.09 & 1.16 & 1.28 & 1.50 & 1.72 & 1.69 & 1.04 \\
\hline 1.066 & 1.01 & 1.02 & 1.02 & 1.02 & 1.03 & 1.03 & 1.04 & 1.04 & 1.06 & 1.08 & 1.14 & 1.23 & 1.42 & 1.63 & 1.67 & 1.04 \\
\hline 1.068 & 1.01 & 1.02 & 1.02 & 1.02 & 1.02 & 1.03 & 1.03 & 1.04 & 1.05 & 1.06 & 1.11 & 1.19 & 1.35 & 1.54 & 1.65 & 1.05 \\
\hline 1.070 & 1.01 & 1.02 & 1.02 & 1.02 & 1.02 & 1.02 & 1.03 & 1.03 & 1.04 & 1.06 & 1.09 & 1.16 & 1.29 & 1.46 & 1.62 & 1.05 \\
\hline 1.072 & 1.01 & 1.01 & 1.02 & 1.02 & 1.02 & 1.02 & 1.02 & 1.03 & 1.04 & 1.05 & 1.08 & 1.14 & 1.24 & 1.39 & 1.58 & 1.05 \\
\hline
\end{tabular}


No. 2

March 2012
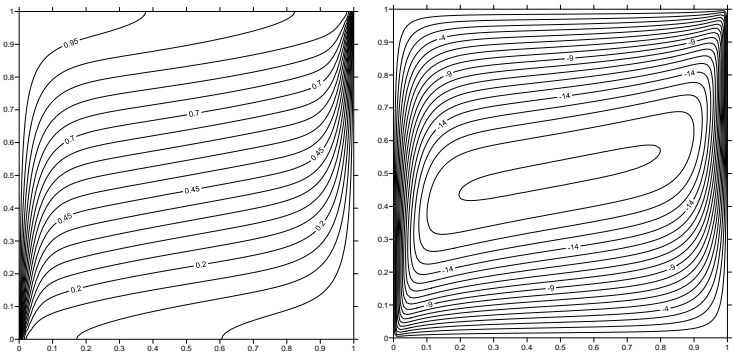

(a)

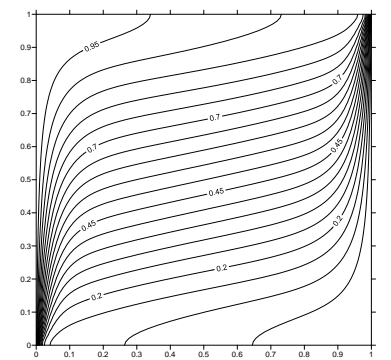

(b)
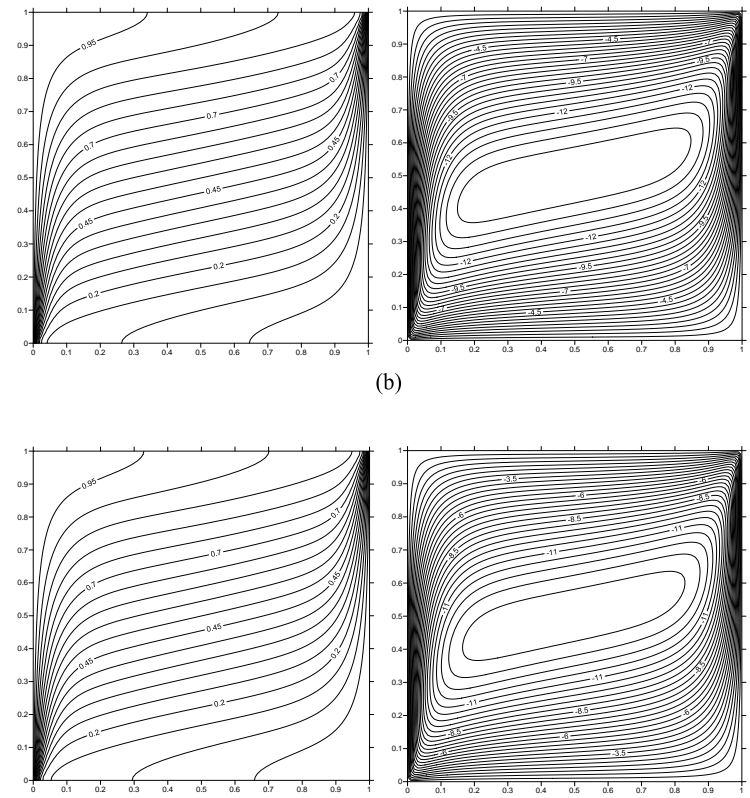

(c)
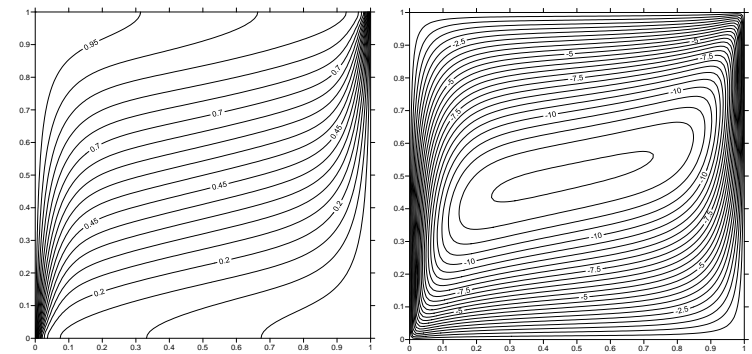

(d)
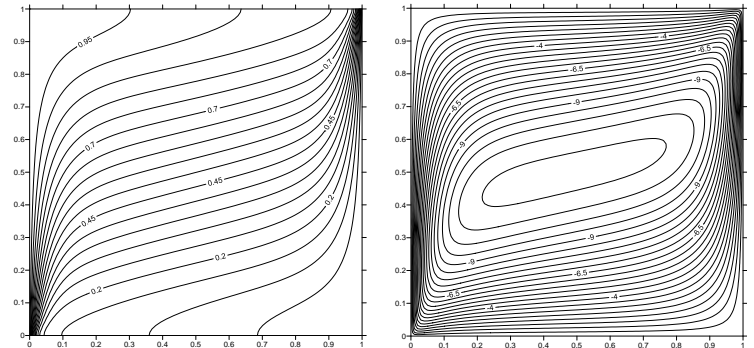

(e)
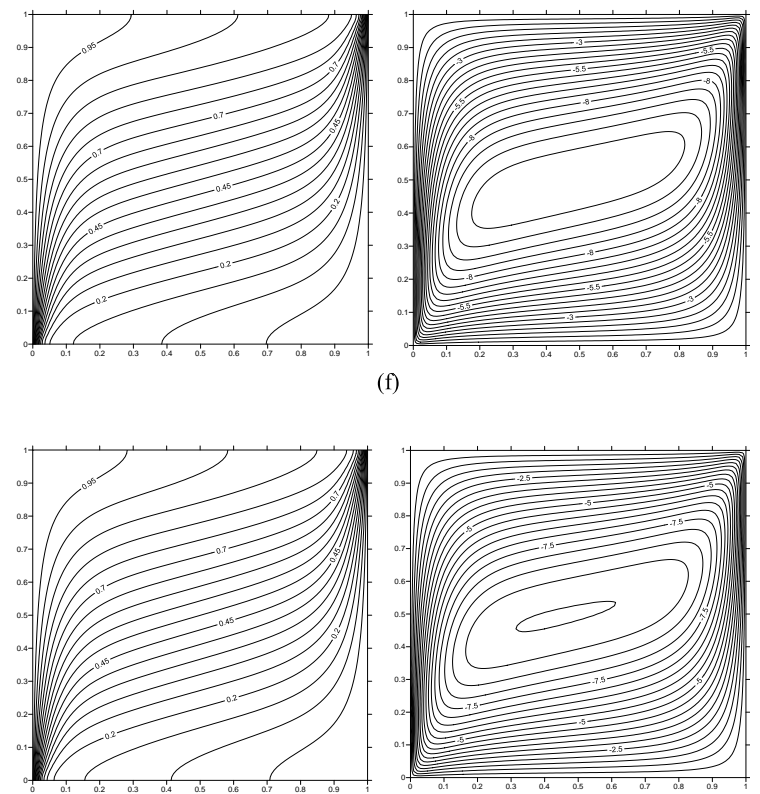

(g)
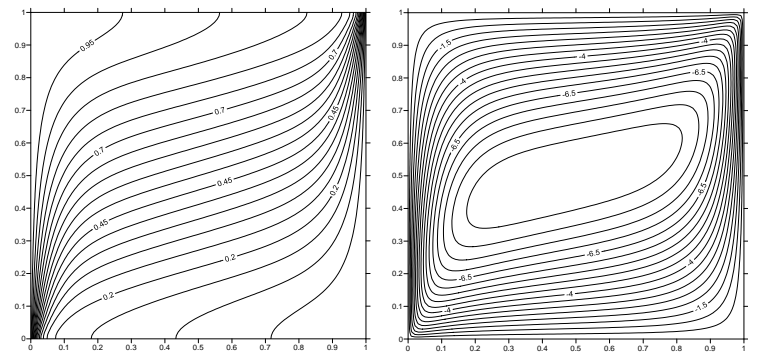

(h)

Fig.(4) shows the isotherms and streamlines for the cases:
(a) $-P_{r e}=1.1, T_{r e}=1.014$.
(e) $-P_{r e}=1.15, T_{r e}=1.02$.
(b) $P_{r e}=1.12, T_{r e}=1.016$.
(f) $-P_{r e}=1.16, T_{r e}=1.022$
(c) $-P_{r e}=1.13, T_{r e}=1.018$.
(g)- $P_{r e}=1.17, T_{r e}=1.024$.
(d) $-P_{r e}=1.14, T_{r e}=1.02$.
(h) $-P_{r e}=1.18, T_{r e}=1.024$. 


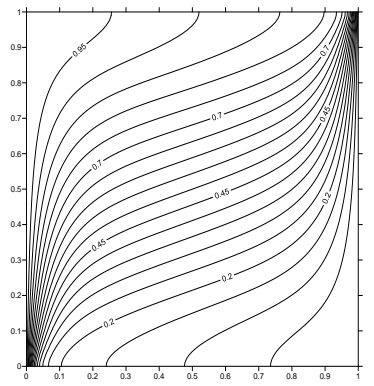

(a)
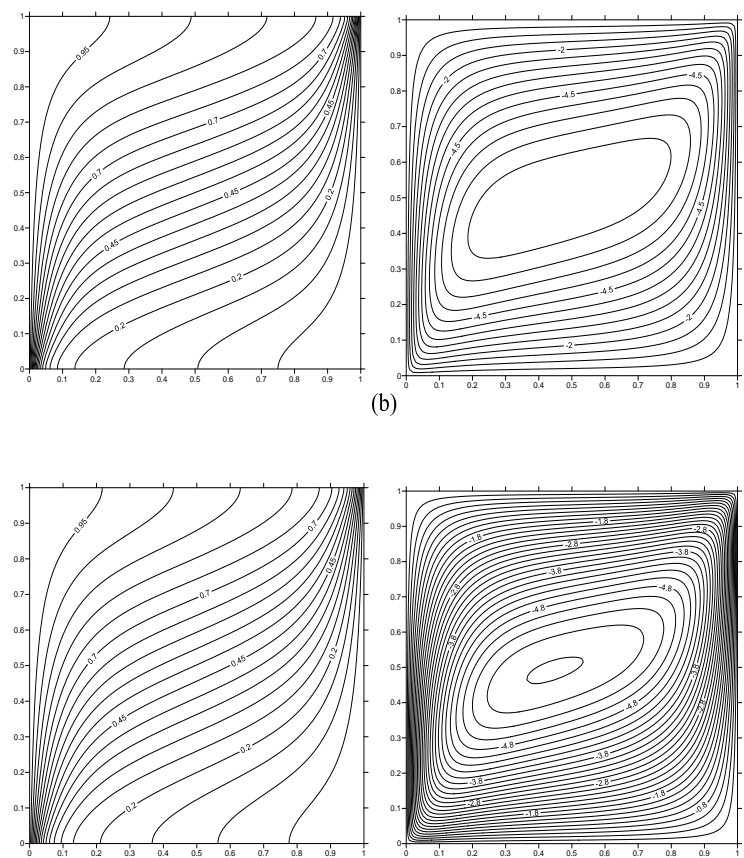

(c)
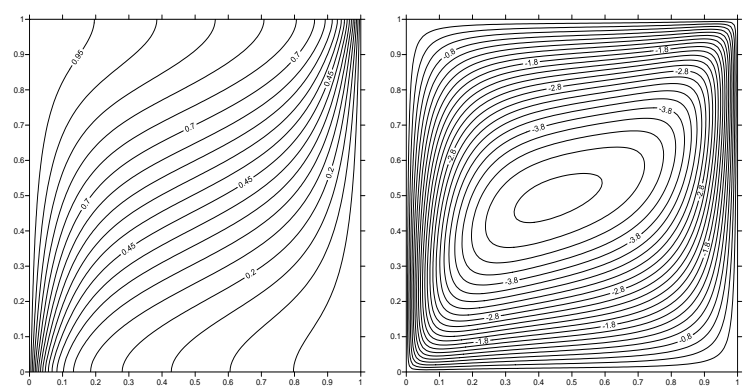

(d)
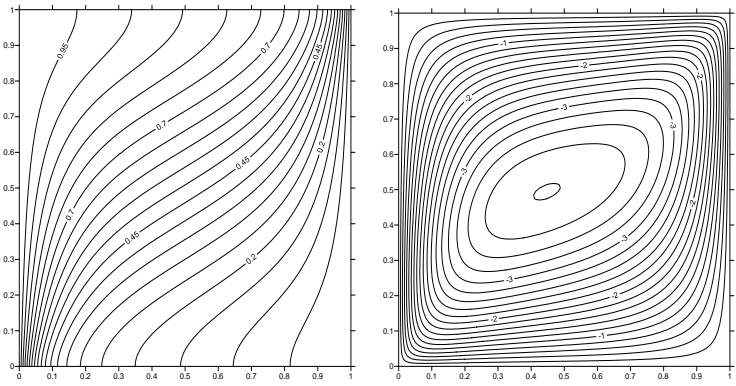

(e)
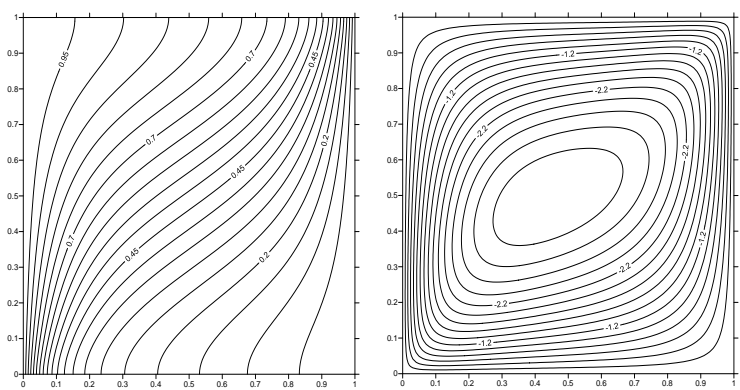

(f)
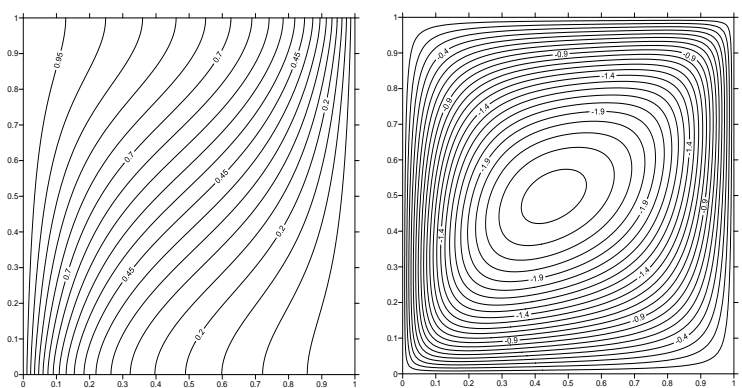

(g)
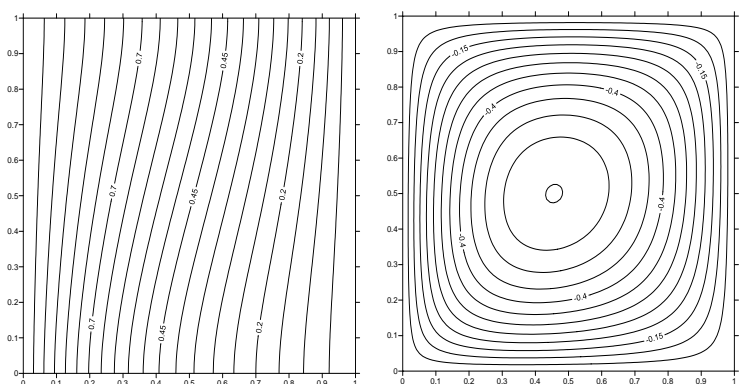

(h)

Fig.(5) shows the isotherms and streamlines for the cases:
(e) $-P_{r e}=1.2, T_{r e}=1.026$.
(e)- $P_{r e}=1.35, T_{r e}=1.046$.
(f) $-P_{r e}=1.22, T_{r e}=1.03$.
(f) $-P_{r e}=1.4, T_{r e}=1.052$.
(g) $-P_{r e}=1.26, T_{r e}=1.034$.
(g) $-P_{r e}=1.5, T_{r e}=1.062$.
(h) $-P_{r e}=1.3, T_{r e}=1.04$.
(h) $P_{r e}=1.2, T_{r e}=1.072$. 


\section{Conclusion:}

As a conclusion, there is a very good of heat exchange enhancement when the carbon dioxide temperature and pressure be above the critical point, so that it is suitable to use the supercritical carbon dioxide as coolant when there is need to draw large amounts of heat in limited space. The high values of specific heat and low density make the supercritical $\mathrm{CO}_{2}$ to absorbs large amount of heat energy and it flow more easily through narrow aisles or in a densely porosity medium.

\section{Reference:}

[1]-J.D. Jackson, W.B. Hall, "Forced convection heat transfer to fluids at supercritical pressure, Turbulence Forced Convection in Channels and Bundles", Hemisphere, New York, vol. 2, (1979), pp. 563-611.

[2]-Ioan I. \& Derek B., "Convective Heat Transfer: Mathematical and Computational Modeling of Viscous Fluids and Porous Media", Elsevier Science, (2001).

[3]-Bejan, A., \& Allan D.," Heat Transfer Handbook", John Wiley \& Sons, Inc. (2003).

[4]-Rolando A. "Natural Convection Heat Transfer in Supercritical Fluid", M. Sc. Thesis, Mechanical Engineering, University of Puerto Rico, (2004).

[5]-Chaobin Danga, Eiji Hihara, "In-tube cooling heat transfer of supercritical carbon dioxide. Part 1. Experimental measurement" International Journal of Refrigeration, Vol. 27, (2004), pp. 736-747.

[6]-Romney B. Duffey \& Igor L. Pioro, "Experimental heat transfer of supercritical carbon dioxide flowing inside channels (survey)", Nuclear Engineering and Design,Vol. 235, (2005), PP. 913-924.

[7]-X. Cheng, B. Kuang, Y.H. Yang, "Numerical analysis of heat transfer in supercritical water cooled flow channels" Nuclear Engineering and Design, Vol. 237, (2007), pp. 240252.

[8]-S. He, W.S. Kim, J.D. Jackson, “A computational study of convective heat transfer to carbon dioxide at a pressure just above the critical value" Applied Thermal Engineering, Vol. 28, (2008), pp. 1662-1675.

[9]-Pei-Xue Jiang *, Run-Fu Shi, Chen-Ru Zhao, Yi-Jun Xu, "Experimental and numerical study of convection heat transfer of $\mathrm{CO}_{2}$ at supercritical pressures in vertical porous tubes", International Journal of Heat and Mass Transfer, Vol. 51. (2008), pp. 6283-6293.

[10]- Pei-Xue Jiang, Yu Zhang, Run-Fu Shi, "Experimental and numerical investigation of convection heat transfer of $\mathrm{CO}_{2}$ at supercritical pressures in a vertical mini-tube", International Journal of Heat and Mass Transfer, Vol. 51, (2008), pp. 3052-3056.

[11]- Yoon-Yeong Bae, \& Hwan-Yeol Kim, "Convective heat transfer to $\mathrm{CO}_{2}$ at a supercritical pressure flowing vertically upward in tubes and an annular channel", Experimental Thermal and Fluid Science, Vol. 33, (2009), PP. 329-339.

[12]- S. M. Liao, T. S. Zhao, "Measurements of Heat Transfer Coefficients From Supercritical Carbon Dioxide Flowing in Horizontal Mini/Micro Channels" Journal of Heat Transfer, (2002), Vol. 124, pp. 413-420. 